\title{
Structure-reactivity study of $O$-tosyl Cinchona alkaloids in their new synthesis and in hydrolysis to 9-epibases. Unexpected formation of cinchonicine enol tosylate accelerated by microwave activation
}

\author{
Teodozja M. Lipińska, *a Katarzyna Piechocka ${ }^{a}$, Monika Denisiuk ${ }^{\mathrm{a}}$, Beata Chmiel ${ }^{\mathrm{b}}$ \\ and Agnieszka Skórska-Stania ${ }^{\text {b }}$ \\ ${ }^{a}$ Institute of Chemistry, University of Siedlce. ul. 3 Maja 54, 08-110 Siedlce, Poland \\ ${ }^{b}$ Faculty of Chemistry, Jagiellonian University, ul. R. Ingardena 3, 30-060 Kraków, Poland \\ E-mail: tlip@uph.edu.pl
}

\begin{abstract}
New methods for $O$-tosylation of the natural Cinchona alkaloids have been discovered as a biphasic processes with $\mathrm{Bu}_{3} \mathrm{~N}$ as a catalyst. The optimized excess of tosyl chloride, necessary for transformation of each of the four alkaloids into $O$-tosyl derivative, decreases in the following order: quinine, quinidine, cinchonidine and cinchonine. The same decreasing order has been noticed for the hydrolysis rate of the appropriate tosylates to 9-epibases. Difficult conversion of $O$-tosylcinchonine in the hydrolytic medium of aqueous tartaric acid gives 9-epicinchonine together with parallel formation of cinchonicine enol tosylate. The latter product is obtained as the main when both cinchonine and cinchonidine tosylates react in the presence of salicylic acid under controlled microwave heating. On the basis of X-ray structure of the new alkene product, the stereoselective syn-E2 quinuclidine ring opening process, competing to the $\mathrm{S}_{\mathrm{N}} 2$ hydrolysis is postulated for this transformation.
\end{abstract}

Keywords: Biphasic $O$-tosylation, conformational analysis, cinchonicine, microwave enhancement, X-ray structure

\section{Introduction}

Molecular diversity of the four main natural Cinchona alkaloids: quinine 1a, quinidine 1b, cinchonidine $\mathbf{2 a}$ and cinchonine $\mathbf{2 b}$ (Scheme 1) results in their various biological activity. ${ }^{1,2}$ The Cinchona alkaloids and their derivatives are highly useful as chiral ligands and catalysts for a wide variety of asymmetric synthesis. ${ }^{3,4}$ The natural molecules are diastereomeric erythro-1,2aminoalcohols, ${ }^{5.6}$ while the Cinchona 9-epibases 1c,d and 2c,d, first discovered by Rabe, ${ }^{7}$ are threo diastereomers which do not possess medicinal value. ${ }^{8}$ Steric and structural effects are 
important for biological activity and chemical reactivity of Cinchona alkaloids and play the key role in various catalytic induction of chirality in asymmetric syntheses. ${ }^{9}$

Recently, C9-O-derivatives of Cinchona alkaloids have attracted considerable attention, as they have the functional group that introduces steric hindrance between quinuclidine and quinoline moieties and modifies polarity that is lower than in the original alkaloids. ${ }^{10}$ The hydrolysis of the $O$-tosyl compounds $\mathbf{3 a}, \mathbf{b}$, and $\mathbf{4 a , b}$ as derivatives of natural erytroaminoalcohols 1a,b and 2a,b, leads to 9-epibases $\mathbf{1 c}, \mathbf{d}$ (for $\mathbf{1 a}, \mathbf{b}$ ) and $\mathbf{2 c , d}$ (for 2a,b) with inverted C9 configuration and threo configuration in the area of C8-C9. This reaction was first conducted by Suszko and co-workers almost eighty years ago. ${ }^{11-13}$ They discovered that the weak acid was the only proper aqueous medium for hydrolysis of $O$-tosyl Cinchona alkaloids, however, it was not efficient for synthesis of 9-epicinchonine $\mathbf{2 d}$ by this way. They described slow hydrolysis of $O$-tosyl cinchonine $\mathbf{4 b}$ and incomplete conversion of its sulfonate group. ${ }^{13}$ In more recent investigations of the Hoffmann group, many side processes have been observed in various conditions directed to hydrolysis of $\mathbf{4 b}$. It has been established that the efficient method for C9 epimerization of the natural Cinchona alkaloids is the weak acid hydrolysis of their Omesyl derivatives, where steric effects lose their significance. ${ }^{5 b, 14}$ However recently, the Mitsunobu inversion has been elaborated for preparation of Cinchona 9 -epibases. ${ }^{15}$

\section{Natural molecules}

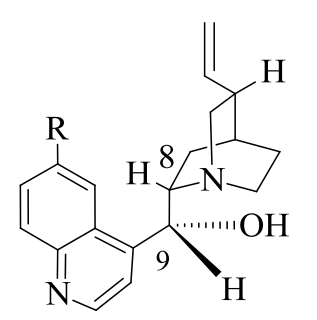

$8 S 9 R\left\{\begin{array}{l}\text { 1a: } \mathrm{R}=\mathrm{OMe} \\ \text { 2a: } \mathrm{R}=\mathrm{H}\end{array}\right.$

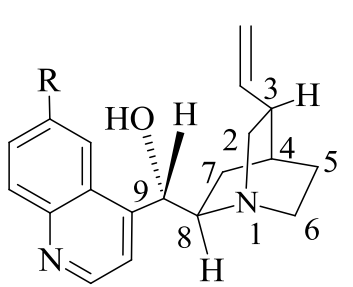

$8 R 9 S$

$\{\mathrm{b}: \mathrm{R}=\mathrm{OMe}$ $\stackrel{\text { (i) }}{\longrightarrow}$

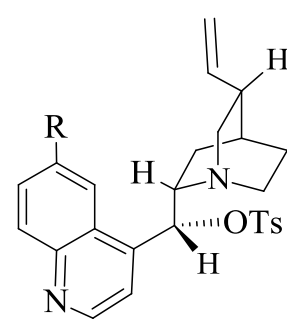

(ii)

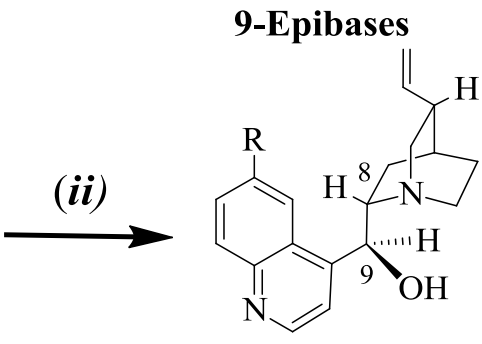

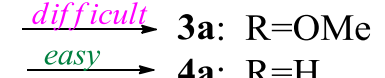

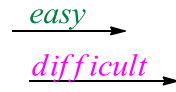

1c: $\mathrm{R}=\mathrm{OMe}$

2c: $\mathrm{R}=\mathrm{H}$

$8 S 9 S$

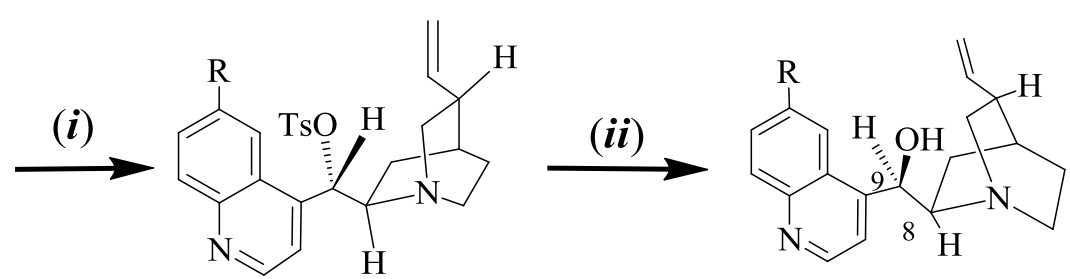

difficult

2b: $\mathrm{R}=\mathrm{H}$

3b: $\mathrm{R}=\mathrm{OMe}$

4b: $\mathrm{R}=\mathrm{H}$

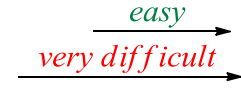

$\left.\begin{array}{l}\text { 1d: } \mathrm{R}=\mathrm{OMe} \\ \text { 2d: } \mathrm{R}=\mathrm{H}\end{array}\right\} 8 R 9 R$

Scheme 1. Transformation of the natural Cinchona alkaloids 1a,b $(8 S, 9 R), \mathbf{2 a , b}(8 R, 9 S)$ into 9-epibases 1c,d, $(8 S, 9 R), \mathbf{2 c}, \mathbf{d}(8 R, 9 R)$ via $O$-tosyl derivatives $\mathbf{3 a}, \mathbf{b}, \mathbf{4 a}, \mathbf{b}$ : (i): retention of C9 in $O$-tosylation with $\mathrm{TsCl}$, (ii): inversion of $\mathrm{C} 9$ configuration in hydrolysis of tosylates in the weak acid medium. 
As a continuation of our work on the structure-properties relationship of Cinchona alkaloids, ${ }^{16}$ we report here the new method of synthesis of $O$-tosyl derivatives $\mathbf{3 a , b}$ and $\mathbf{4 a} \mathbf{a}, \mathbf{b}$ with the stress on research of their reactivity differences in the hydrolysis to 9 -epibases $\mathbf{1 c}, \mathbf{d}$, and $\mathbf{2 c , d}$.

\section{Results and Discussion}

\section{New synthesis of $O$-tosyl Cinchona alkaloids}

The tosylation methodologies were gradually improved. Long ago, two methods with an excess of tosyl chloride were used for $O$-tosylation of the Cinchona alkaloids. ${ }^{11-13}$ In the first of them, alkaloid $1 \mathbf{a}$ or $\mathbf{1 b}$ reacted in the biphasic system of benzene-aqueous $50 \% \mathrm{KOH}$ solution. In the second method, less soluble $\mathbf{2 a}$ or $\mathbf{2 b}$ reacted with $\mathrm{TsCl}$ in the pyridine medium. Next, $O$ tosylation was performed via a two-step procedure: formation of alcoholates with strong base $\left(\mathrm{NaH}\right.$, or BuLi), followed by reaction with tosyl chloride. ${ }^{16 \mathrm{~d}, 17}$ Recently, Cinchona alkaloid tosylates have been obtained in the refluxed $\mathrm{THF}$ with $\mathrm{TsCl}$ excess, in the presence of triethylamine and DMAP. ${ }^{14 c}$

In our initial experiments we tested reaction of Cinchona alkaloids without external tertiary amine, with an excess of tosyl chloride in the vigorously stirred biphasic system dichloromethane - aqueous $\mathrm{KOH}$. We observed slow transformation to the appropriate tosylate (TLC control). Next, triethylamine was added to the reaction mixture and considerable increase in the conversion rate was noticed. Then, we chose tributylamine as an effective interface transfer agent for the room-temperature $O$-tosylation. Finally, we examined tributylamine in the catalytic quantity in two biphasic systems: liquid-liquid (dichloromethane-aqueous $35 \% \mathrm{KOH}$ in method A); and liquid-solid (dichloromethane-solid powdered anhydrous $\mathrm{KOH}$ in method $\mathrm{B}$ ).

We propose a mechanism with an inter-phase transfer of reagents in $O$-tosylation. Tosyl chloride interacts with $\mathrm{Bu}_{3} \mathrm{~N}$ and gives a $N$-tosyl tributylammonium chloride, which can retain in the organic phase and acts as a tosylation agent for hydroxy function of the alkaloid (Scheme 2). Tributylamine has a role similar to pyridine in conventional acylation and sulfonylation processes of alcohols and amines in the pyridine medium, However in this case it is effective enough in the catalytic amount, since its protonation in the tosylation process can disappear in contact with the aqueous alkaline phase.

However, two ineffective phase interaction processes can run in parallel to $O$-tosylation a) tosyl chloride may be consumed when it is changed into tosylate anion and transferred from the organic phase to the aqueous phase, b) tosyl ester group of the product can be attacked by hydroxyl anion, turning back the main process of $O$-tosylation. These two side processes give excessive consumption of tosyl chloride during $O$-tosylation and therefore it must be used in excess. We have optimized the necessary excess of tosyl chloride for each alkaloid 1a,b, and $\mathbf{2 a}, \mathbf{b}$ in order to maximize the yields of the corresponding $O$-tosylates in the experimental scale of 10 milimoles of starting materials (Table 1). 


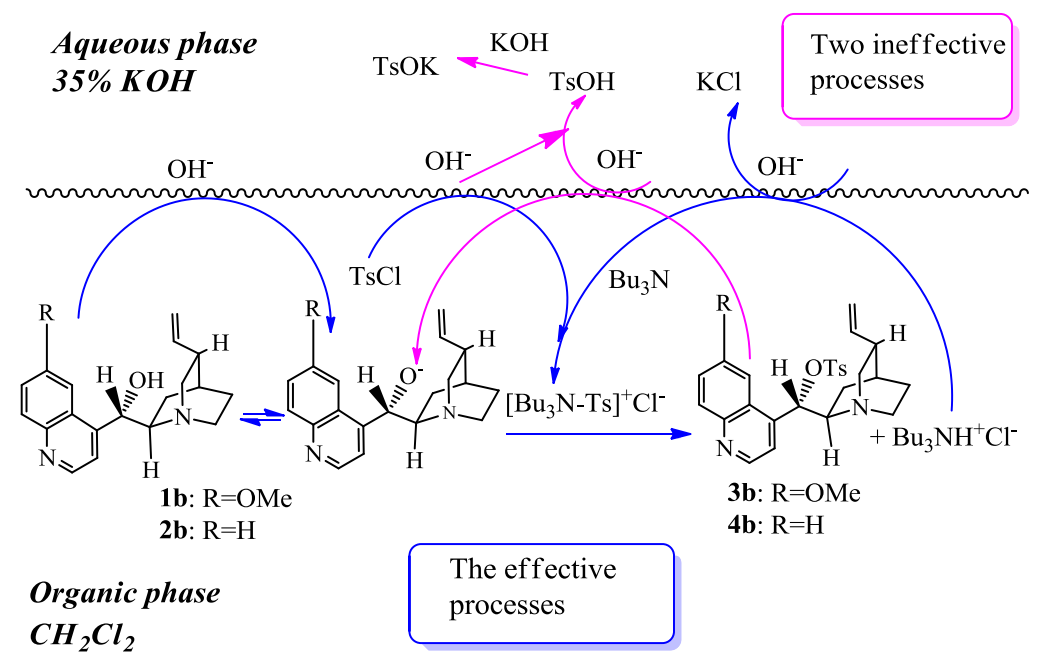

Scheme 2. Liquid-liquid $O$-tosylation of quinidine $(\mathrm{R}=\mathrm{OMe})$ and cinchonine $(\mathrm{R}=\mathrm{H})$ with $\mathrm{Bu}_{3} \mathrm{~N}$ as a catalyst.

Table 1. Comparison of optimized amounts of $\mathrm{TsCl}$ needed for conversion of $\mathbf{1 a}, \mathbf{b}$ and $\mathbf{2 a}, \mathbf{b}$ into $\mathbf{3 a}, \mathbf{b}$ and $\mathbf{4 a , b}$ by Method $\mathrm{A}^{\mathrm{a}}$, product polarity values (as $R_{\mathrm{f}}$ values) and yields

\begin{tabular}{ccccc}
\hline Started alkaloid $^{\mathrm{b}}$ & $\mathrm{TsCl}(\mathrm{mmol})$ & Tosylate number & ${\text { Tosylate } R_{\mathrm{f}}^{\mathrm{c}}}$ Tosylate yield (\%) $^{\mathrm{d}}$ \\
\hline $\mathbf{1 a}$ & 40 & $\mathbf{3 a}$ & 0.85 & 80 \\
$\mathbf{1 b}$ & 35 & $\mathbf{3 b}$ & 0.58 & 76 \\
$\mathbf{2 a}$ & 25 & $\mathbf{4 a}$ & 0.62 & 82 \\
$\mathbf{2 b}$ & 20 & $\mathbf{4 b}$ & 0.55 & 90 \\
\hline
\end{tabular}

${ }^{a}$ Method A: substrate $10 \mathrm{mmol}$ was stirred with $\mathrm{TsCl}$ in the medium of dichloromethane-aqueous $35 \% \mathrm{KOH}, 24 \mathrm{~h}$ at room temperature with $1 \mathrm{mmol}$ of $\mathrm{Bu}_{3} \mathrm{~N}$ ). ${ }^{\mathrm{b}}$ Commercial grade. ${ }^{\mathrm{c}} R_{f}$ values were measured in ethyl acetate-methanol system 10:1. ${ }^{\mathrm{d}}$ After isolation by column chromatography.

It is interesting to note that:

(a) The autocatalytic activity of quinuclidine nitrogen in the Cinchona alkaloid substrates is not sufficient for the $O$-tosylation process, which is significantly slower without tributylamine, the reaction time is noticeably longer and much higher excess of tosyl chloride is necessary.

(b) We found that for the synthesis of $O$-tosylcinchonine $\mathbf{4 b}$ by our Method A, double excess of tosyl chloride is sufficient, whereas for the preparation of $O$-tosylquinine 3a fourfold excess of tosyl chloride is necessary. The excess of $\mathrm{TsCl}$ needed for synthesis of corresponding $O$-tosyl derivatives decreases in the following sequence: quinine, quinidine, cinchonidine, cinchonine.

(c) As a result of our investigation of Method $\mathrm{B}$, that consisted in the solid $\mathrm{KOH}$-organic solvent tosylation of Cinchona alkaloids in the presence of $\mathrm{Bu}_{3} \mathrm{~N}$ as a catalyst, we found that only the 
$50 \%$ excess of tosyl chloride is sufficient for each alkaloid to transform into its corresponding tosylate in yield 70-80\% together with unchanged alkaloids (TLC control).

d) Both of our phase transfer methods used for Cinchona alkaloid $O$-tosylation are processes which can be performed at the room temperature, giving yields comparable to those obtained in refluxing THF with $\mathrm{NEt}_{3}$ and DMAP. ${ }^{14}$

\section{Examination of $\boldsymbol{O}$-tosyl Cinchona alkaloids' hydrolysis}

The structure-reactivity relationship was observed during hydrolysis of the four tosylates in a diluted solution of tartaric acid in hot water. This is shown in Table 2, Entry 1-4, as different reaction times necessary for full conversion of compounds $\mathbf{3 a}, \mathbf{b}$ and $\mathbf{4 a}, \mathbf{b}$. Molecules with the methoxy group, i.e. 3a and $\mathbf{3 b}$ react easily (15 $\mathrm{min}$ and $30 \mathrm{~min}$ ), giving correspondingly 9epiquinine 1c and 9-epiquinidine 1d as the main product, with a small amount of regenerated starting alkaloid $\mathbf{1 a}$ and $\mathbf{1 b}$. Cinchonidine tosylate 4a reacts slowly to $\mathbf{2 c}$ (6 h, Entry 3$)$, but with a good selectivity. The 9-epibases $\mathbf{1 c}, \mathbf{1 d}$ and $\mathbf{2 c}$ can be obtained by this way in the preparative scale with good yields in the purity above $98 \%$ (determined by ${ }^{1} \mathrm{H}$ NMR after isolation by the column chromatography). However, hydrolysis of cinchonine tosylate $\mathbf{4 b}$ runs much slower (20 h, Entry 4), giving the mixture of three products. When we applied careful column chromatography with methoxethanol, a trace of regenerated cinchonine $\mathbf{2 b}\left(R_{f}=0.47\right)$ was isolated first. Then, a new compound $\mathbf{5}$ possessing lower polarity $\left(R_{f}=0.39\right)$ was collected. Next, 9-epicinchonine $\mathbf{2 d}\left(R_{f}=0.31\right)$ was eluted with the mixtures of 2-methoxyethanol and methanol. The new product 5 was identified by spectral data as a product of quinuclidine ring cleavage in the intramolecular piperidine elimination (Scheme 3), and can be called cinchonicine (or Pasteur's cinchotoxine) enol tosylate. Microwave enhancement of the hydrolysis of $\mathbf{4 b}$ (Table 2, Entry 5) gives the equal amounts of both $\mathbf{2 d}$ and $\mathbf{5}$. We discovered that the latter compound is formed as the main product (Scheme 3) when cinchonine tosylate $\mathbf{4 b}$ reacts with the excess of salicylic acid in a medium of water/ethylene glycol under controlled microwave heating (Table 3, Entry 6).

In the next step of our experiments we found that the same cinchonicine enol tosylate 5 can also be obtained as the main product (together with epicinchonidine $\mathbf{2 c}$ and cinchonidine 2a) from $O$-tosylcinchonidine $\mathbf{4 a}$ irradiated by microwaves with an excess of salicylic acid (Table 2, Entry 7). However, in this case, it is difficult to separate pure 5 from the reaction mixture since its $R_{f}$ value (0.39) is near to the $R_{f}$ value observed for 9-epicinchonidine $2 \mathbf{c}(0.35)$

We were the first to observe that the Pasteur's type cleavage of $O$-tosylcinchonine $\mathbf{4 b}$ occurs in the hydrolytical medium, leading to formation of the new compound, cinchonicine enol tosylate 5. We have found out that this process is competing to hydrolysis of $O$-tosylcinchonine 4b in conventional conditions (diluted aqueous tartaric acid), and that it is the main reaction under controlled microwave heating of both $\mathbf{4 b}$ and $\mathbf{4 a}$ with an excess of salicylic acid in the ethylene glycol-water medium. This type of transformation is similar to the Pasteur's cleavage of the natural Cinchona alkaloids to cinchotoxine (ketone) when they are heated with organic or mineral acids. ${ }^{5,6}$ Toxine rearrangement of Cinchona alkaloids with acetic acid in the presence of 
acetic anhydride has been investigated, ${ }^{18}$ and the cinchonicine enol acetate formation has been postulated. However, this compound, similar to 5, has not been isolated so far.

Table 2. Yields and $R_{\mathrm{f}}$ values of 9-epibases 1c,d and $\mathbf{2 c}, \mathbf{d}$ obtained in different conditions from corresponding tosylates. Yields and $R_{f}$ values of the new product $\mathbf{5}$ and regenerated substrates 1a,b, 2a,b

\begin{tabular}{|c|c|c|c|c|c|c|}
\hline \multirow[t]{2}{*}{ Entry } & \multirow{2}{*}{$\begin{array}{l}\text { Substrate } \\
\text { No } /\left[R_{\mathrm{f}}\right]^{\mathrm{a}}\end{array}$} & \multicolumn{2}{|c|}{ Tosylate hydrolysis } & \multicolumn{3}{|c|}{ Reaction products } \\
\hline & & No & Time & No & $R_{\mathrm{f}}^{\mathrm{a}}$ & Yield $[\%]^{\mathrm{b}}$ \\
\hline 1 & 1a [0.63] & $3 \mathbf{a}$ & $15 \min ^{\mathrm{c}}$ & $1 \mathrm{c}$ & 0.39 & 75 \\
\hline 2 & $\mathbf{1 b}[0.61]$ & $3 \mathbf{b}$ & $30 \min ^{c}$ & 1d & 0.46 & 65 \\
\hline 3 & 2a $[0.54]$ & $4 a$ & $6 h^{c}$ & $2 c$ & 0.35 & 70 \\
\hline 4 & $\mathbf{2 b}[0.47]$ & $4 b$ & $20 \mathrm{~h}^{\mathrm{c}}$ & $5+2 d$ & $0.39 ; 0.31$ & $15 ; 45$ \\
\hline 5 & $\mathbf{2 b}[0.47]$ & $4 b$ & $20 \min ^{\mathrm{d}}$ & $5+2 d$ & $0.39 ; 0.31$ & $30 ; 30$ \\
\hline 6 & $\mathbf{2 b}[0.47]$ & $4 b$ & $30 \min ^{\mathrm{e}}$ & $2 b+5+2 d$ & $0.47 ; 0.39 ; 0.31$ & $15 ; 60 ; 15$ \\
\hline 7 & $\mathbf{2 a}[0.54]$ & $4 \mathbf{a}$ & $15 \min ^{e}$ & $2 a+5+2 c$ & $0.54 ; 0.39 ; 0.35$ & $10 ; 40 ; 20$ \\
\hline
\end{tabular}

${ }^{\text {a }}$ Values of $R_{\mathrm{f}}$ were measured on silica-gel TLC plates in 2-methoxyethanol. ${ }^{\mathrm{b}}$ Yields of product isolated by column chromatography. ${ }^{\mathrm{c}}$ Procedure 1 : Tosylate $(10 \mathrm{mmol})$ was heated at $92-95{ }^{\circ} \mathrm{C}$ with the aqueous solution of tartaric acid $(15 \mathrm{mmol}: 0.1 \mathrm{M}, 150 \mathrm{ml})$. ${ }^{\mathrm{d}}$ Procedure 2 : Tosylate $4 \mathbf{b}$ (4 mmol) was added to $20 \mathrm{~mL}$ of water containing tartaric acid $(6 \mathrm{mmol})$ and was irradiated in an open vessel (Synthewave 402 reactor, Prolabo) at the controlled temperature of $95{ }^{\circ} \mathrm{C}$. ${ }^{\mathrm{e}}$ Procedure 3: Tosylate $\mathbf{4 b}$ or $\mathbf{4 a}(2 \mathrm{mmol})$ and salicylic acid $(20 \mathrm{mmol})$ were added to $20 \mathrm{~mL}$ of $50 \%$ ethylene glycol water solution and irradiated in an open vessel (Synthewave 402 reactor, Prolabo) at the controlled temperature of $95^{\circ} \mathrm{C}$.

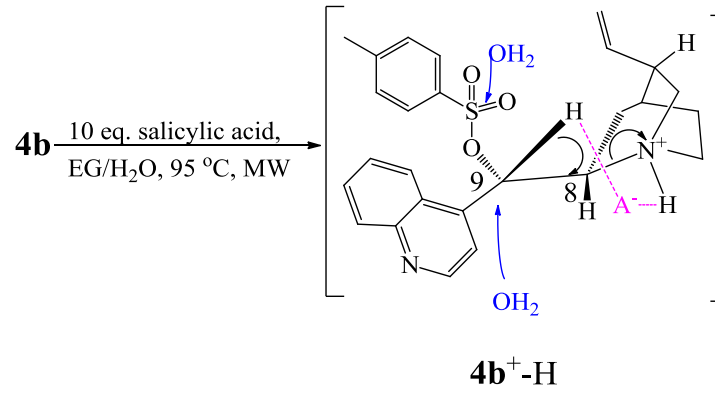

$\mathbf{4} \mathbf{b}^{+}-\mathrm{H}$

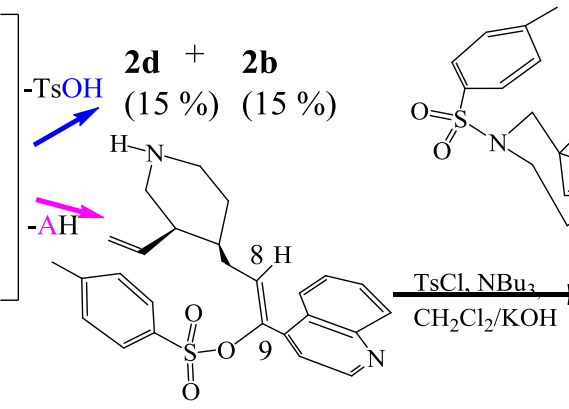

5

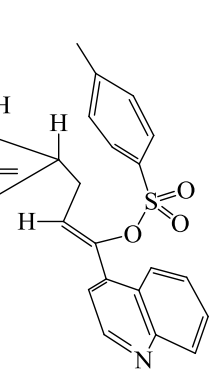

6

Scheme 3. Possible ways of transformation of $\mathbf{4 b}-\mathrm{H}^{+}$in the syn-open conformation: hydrolysis with $\mathrm{C} 9$ inversion to $\mathbf{2 d}$ or with retention to $\mathbf{2 b}$ (by $\mathrm{H}_{2} \mathrm{O}$ attack at the $\mathrm{C} 9$ or at the sulfur of sulfonate) versus $\mathrm{H}-\mathrm{C} 9$ elimination together with N1-C8 bond cleavage towards the cinchonicine enol tosylate 5, which is next converted to sulfonamide $\mathbf{6}$. 


\section{The sulfonamide derivative 6 preparation for crystal and molecular structure determination by $\mathrm{X}$-ray diffraction}

The ${ }^{1} \mathrm{H}$ NMR spectrum of the new product 5 shows a signal picture proper for four alkene protons (5.0-6.2 ppm), where three of them display the vinyl group. The signal of the new enolalkene proton is visible as a triplet at $5.75 \mathrm{ppm}$. It is interesting that each of the four piperidine protons bonded with $\alpha$-carbons (2.50-3.20 ppm) gives separated signal, which means that only one conformation of piperidine can exist as dominant. Therefore, axial and equatorial protons do not give the average signals. The piperidine ring conformation with the large 4-substituent in equatorial position seems to be most probable. However, we cannot determine the enolane geometry from ${ }^{1} \mathrm{H}$ NMR as the NOE effects were observed as unclear.

The product $\mathbf{5}$ is in an oily form. We decided to transform it into sulfonamide derivative $\mathbf{6}$ in reaction with tosyl chloride in the presence of $\mathrm{BuEt}_{3}$ (Scheme 3). The crystals appropriate for the X-ray experiment were obtained after purification by column chromatography and slow evaporation of aqueous-ethanol solution.
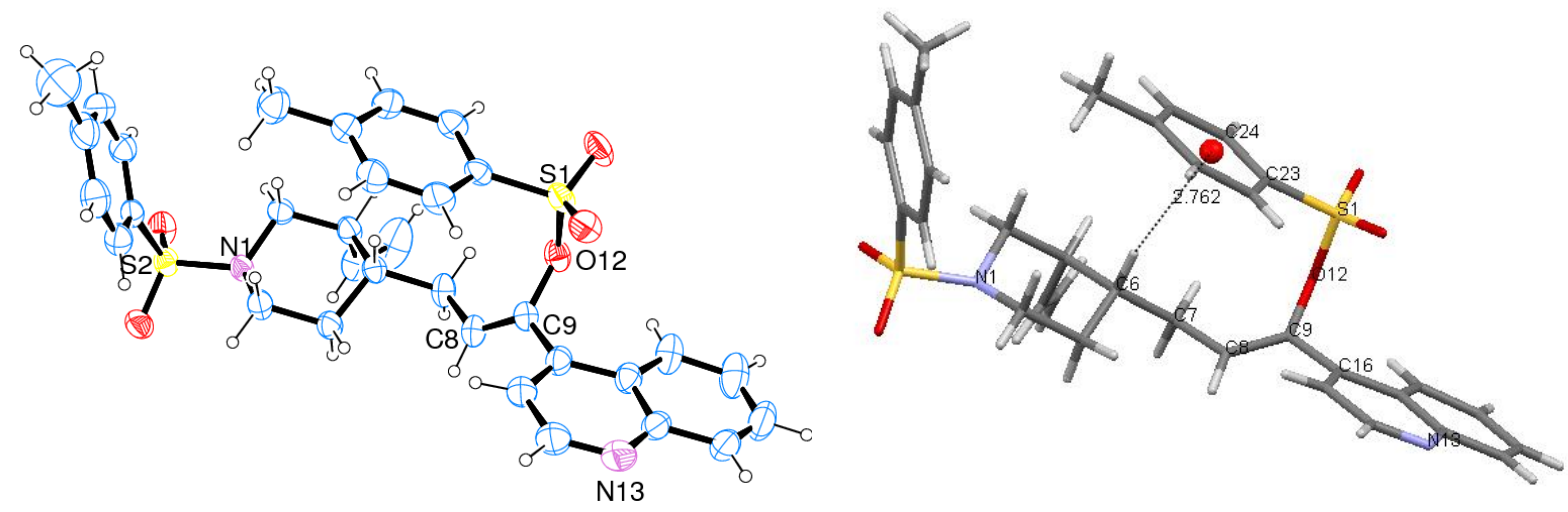

Figure 1. Ortep drawing of 6 with displacement ellipsoids shown at the $30 \%$ probability level (left) and intramolecular interaction (right), where the red ball shows the center of the $O$-tosyl aromatic ring.

As shown in the projections of the molecule of the compound 6 (Figure 1), the configuration $Z$ should be assigned to the double bond $\mathrm{C} 8=\mathrm{C} 9$. The shape of the molecule seems to be determined by the intramolecular $\mathrm{C}-\mathrm{H} \cdots \pi$ interactions (e.g. the distance C6-H $\cdots \pi=2.762 \AA$ ) which are most probably responsible for the conformation of the whole molecule. ${ }^{19}$ The aromatic ring of the tosylate group and the quinoline ring are almost planar and almost parallel to each other, the angle between their planes being about $8^{\circ}$. The $N$-tosyl moiety is strongly deviated from the $O$-tosyl group (the angle between the two planes equals $56^{\circ}$ ). The classical intermolecular hydrogen bonds do not exist in the crystal structure of the compound $\mathbf{6}$, however the weak hydrogen bonds, $\mathrm{C}-\mathrm{H} \cdots \mathrm{O}$ can play a crucial part in controlling the crystal packing (see Supplementary Material). 


\section{Comparative conformational analysis of $\mathrm{N}-1$ protonated forms of $4 \mathrm{a}$ and $4 \mathrm{~b}$ as a method explaining potential formation of transition states towards hydrolysis to 9-epibases versus intra-molecular elimination to 5 .}

The course of hydrolysis of $O$-tosyl derivatives $\mathbf{4 a}$ and $\mathbf{4 b}$ with the inversion of configuration at C9 must occur as the $\mathrm{S}_{\mathrm{N}} 2$ nucleophilic attack of water molecule on the side opposite to the tosylate leaving group in the substrate protonated at the quinuclidine nitrogen. Theoretical considerations assume four energetically possible conformers of Cinchona alkaloid molecules: ${ }^{9 \mathrm{a}}$ two closed (anti and syn) and two open (anti and syn). The syn-open conformation of $O$-tosyl cinchonine $\mathbf{4 b}$ is the most required for 9-epicinchonine $\mathbf{2 d}$ formation (see Scheme 3 ).

Recently, we have published results of the X-ray structure analysis and theoretical calculations of the diastereoisomeric molecules $\mathbf{4 a}$ and $\mathbf{4 b}$, which were used to explain their different reactivity in the hydrolysis to the respective 9 -epibases. ${ }^{20}$ The differences in energetic profit during protonation on $\mathrm{N} 1$ atom and in propensity to the conformation change from an anticlosed in the crystals of both neutral molecules to a syn-open one, favored in their weak acid- $\mathrm{S}_{\mathrm{N}} 2$ hydrolysis process, can be correlated with the different reactivity of $\mathbf{4 a}-\mathrm{H}^{+}$and $\mathbf{4 b}-\mathrm{H}^{+}$toward 9epibases. Now, we will tray to elucidate why the competing process occurs towards the cleavage of quinuclidine ring leading to cinchonicine enol tosylate 5 formation.

On the Scheme 4 can be seen the possibility of easy rotations in molecule $4 \mathbf{a}^{+}-\mathrm{H}$ around C8C9 bond (giving closed and open conformers), as well as around C4'-C9 bond (giving syn and anti conformers). The hydrolysis can run as the attack of water molecule at $\mathrm{C} 9$ atom in both open conformers $\mathrm{C}_{\mathrm{a}} 3$ and $\mathrm{C}_{\mathrm{a}} 4$. This creates the possibility for the transition state formation that gives 9-epicinchonidine 2c. The regioselectivity towards $\mathbf{2 c}$ can be experimentally observed in the classical heating of $\mathbf{4 a}$ with aqueous tartaric acid. This indicates that the $\mathrm{S}_{\mathrm{N}} 2$ process runs under kinetic control, that requires accessibility of the rotamers $C_{a} 3$ and $C_{a} 4$ as the energetically privileged. The experimental result shows that the microwave activation of the protonated molecule leads to the formation both of 2c and 5. This fact indicates that the syn-E2 cleavage process, competing to $\mathrm{S}_{\mathrm{N}} 2$ hydrolysis, cannot be conformationally determined. It is forced by the internal microwave activation of $\mathbf{4 a}-\mathrm{H}^{+}$molecule, which can react without conformational preference. In this case, high energetic demand for transition state formation requires simultaneous interaction of the anionic-base $\left(\mathrm{A}^{-}\right)$with quinuclidine cationic nitrogen (electrostatic) and the proton $\mathrm{H}-\mathrm{C} 9$ (acid-base). Theoretical conformational analysis shows that this is possible in all the open and closed conformers (Scheme 4). Moreover, the experiments revealed that the preference towards elimination to $\mathbf{5}$ can be achieved under microwave irradiation of $\mathbf{4 a}-\mathrm{H}^{+}$with the salicylic acid in the aqueous medium.

In the view of considered ways of microwave activation in different types of organic syntheses, ${ }^{21}$ the contribution of microwave catalysis through rotationally hot reactive species ${ }^{22}$ is the most probable reason for the emergence of the second direction of $\mathbf{4 a}^{+}-\mathrm{H}$ transformation towards 5 formation by the cleavage of quinuclidine ring. This none-quilibrium system can be formally described by considering of rotational temperature, which is higher than the translational temperature for the all existing closed and open conformers. 


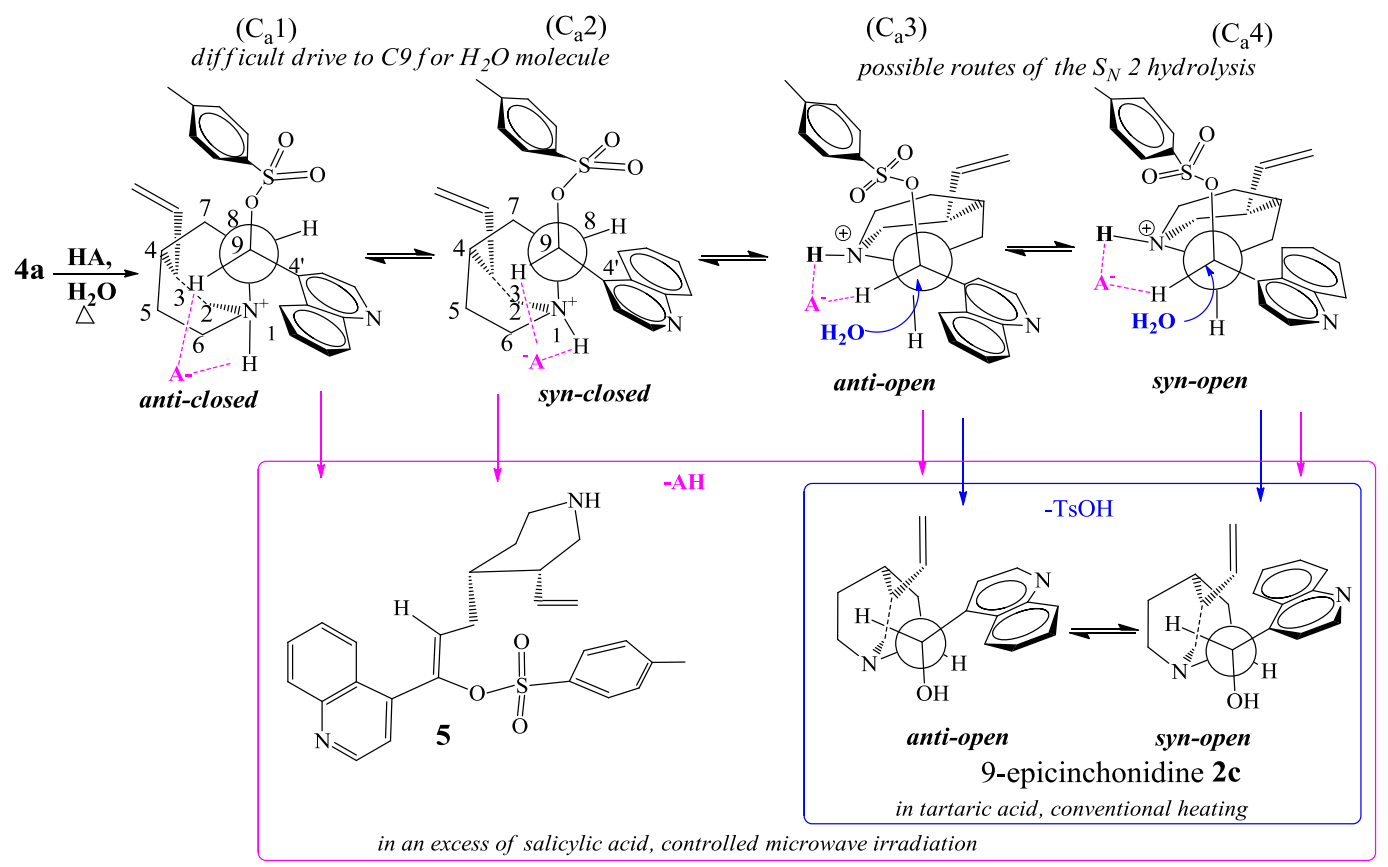

Scheme 4. Hypothetical ways of $\mathbf{4 a}^{+}-\mathrm{H}$ hydrolysis towards formation of $\mathbf{2 c}$ and $\mathbf{5}$.

In the case of the protonated molecule of $O$-tosyl cinchonine $4 \mathbf{b}^{+}-\mathrm{H}$ (Scheme 5), the vinyl group is a tethered element that determines possible rotations. There are difficulties in the rotation around bond $\mathrm{C} 8-\mathrm{C} 9$ that change the closed conformers $\left(\mathrm{C}_{\mathrm{b}} 1\right.$ and $\left.\mathrm{C}_{\mathrm{b}} 2\right)$ into more hindered open conformers $\left(\mathrm{C}_{\mathrm{b}} 3\right.$ and $\left.\mathrm{C}_{\mathrm{b}} 4\right)$. Due to high energetic barrier of rotations, the transition state for the attack of the water molecule on the carbon atom $\mathrm{C}$ 9 in $\mathrm{S}_{\mathrm{N}} 2$ hydrolysis that leads to 9epicinchonine $\mathbf{2 d}$, is difficult to achieve. This is the reason for $O$-tosyl cinchonine $\mathbf{4 b}$ hydrolytic stability in the weak acid medium.

The discussion of conformations leads to the conclusion that in this case a competing reaction with the acid anion as a base can lead to the intramolecular syn-E2 elimination to the alkene 5 possessing the same geometry as that obtained from $\mathbf{4 a}-\mathrm{H}^{+}$. This product can form without conformational preference and was observed both in the prolonged conventional heating of $\mathbf{4 b}-\mathrm{H}^{+}$(Entry 4, Table 2) and under short microwave irradiation at the temperature of $95^{\circ} \mathrm{C}$. The excess of the salicylic acid with the microwave activation leads to prevailing conversion into the cleavage product $\mathbf{5}$. However, in this case, considerable amount of cinchonine $\mathbf{2} \mathbf{b}$ with the retention of $\mathrm{C} 9$ configuration is parallel formed in the course of hydrolysis. It is possible in result of the $\mathrm{O}-\mathrm{SO}_{2}$ bond cleavage after water molecule attack on the sulfonate group of $\mathbf{4} \mathbf{b}^{+}-\mathrm{H}$.

The stereoselectivity that we observed, lead to formation of $Z$-alkene $\mathbf{5}$ from tosylates $\mathbf{4 a}$ and $\mathbf{4 b}$, which confirms that this is the second type of mechanism (three types are mentioned in the literature: ref $^{4}$ pp. 361-363) for the Pasteur cleavage of natural Cinchona alkaloids giving ketone via enol. The fact that the intramolecular piperidine elimination is more plausible when 
the planar salicylate anion $\left(\mathrm{A}^{-}\right)$takes part as a base, instead of the tartrate anion, can be interpreted as a stereoelectronic factor.

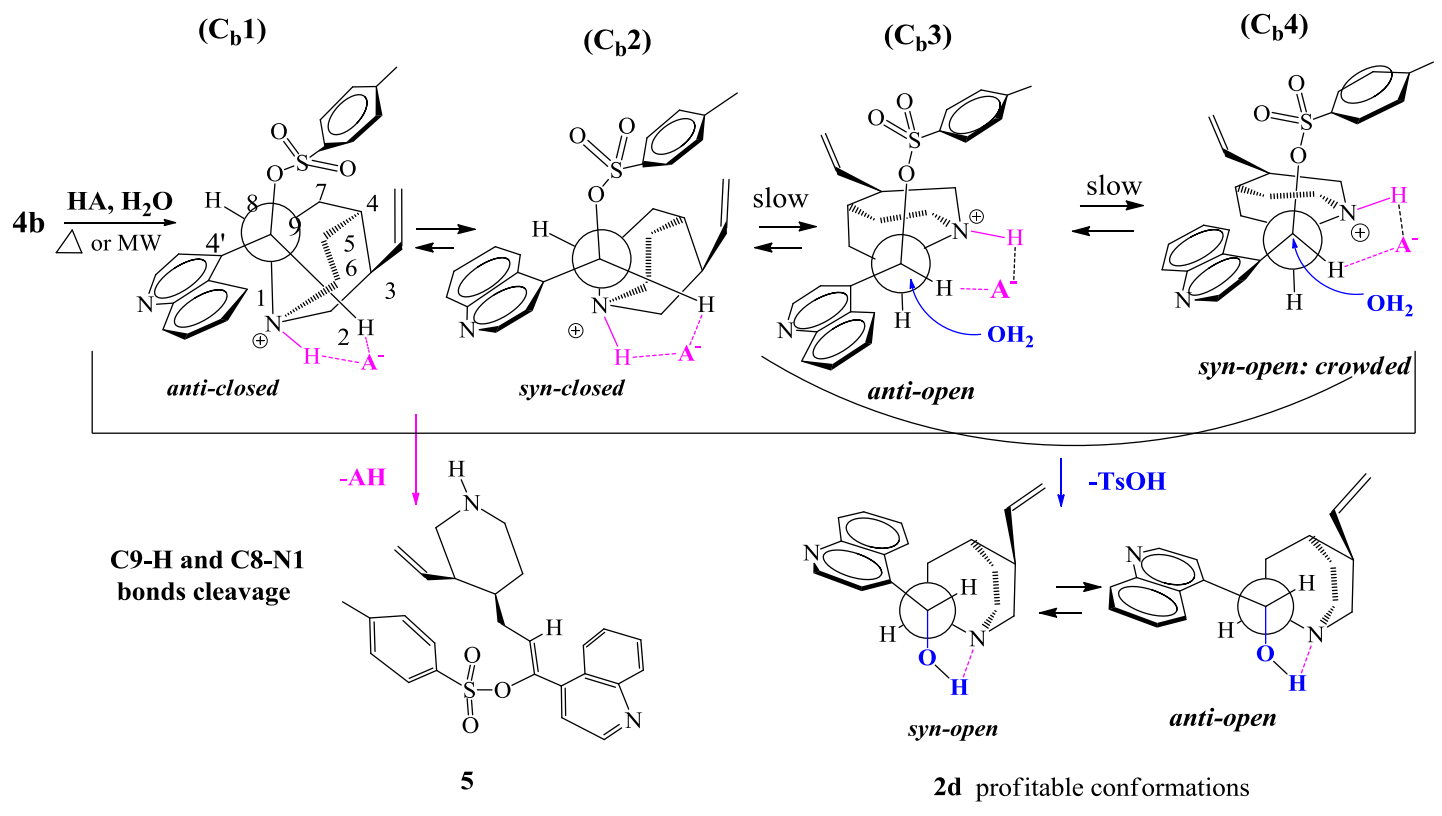

Scheme 5. Conformational analysis of $\mathbf{4 b}$ in the aspect of the two routes of its transformation: intramolecular elimination to $\mathbf{5}$ and the difficult $S_{N} 2$ hydrolysis to $\mathbf{2 d}$.

\section{Conclusions}

We have developed the new methods for the effective and selective transformation of the four natural Cinchona alkaloids into appropriate $O$-tosyl derivatives at room-temperature in biphasic systems using tributylamine as the catalyst. The tosyl esters has been carefully reinvestigated in the hydrolysis-inversion process leading to 9-epibases $\mathbf{1 c}, \mathbf{d}$ and $\mathbf{2 c , d}$. We confirm that the molecules with the methoxy group $\mathbf{3 a}, \mathbf{b}$ are significantly more reactive than cinchonidine and cinchonine tosylates $\mathbf{4 a}$ and $\mathbf{4 b}$. The latter one is the most hydrolytically stable in the substitution process by the water molecule in the weak-acid aqueous medium. Comparative conformational analysis for cinchonidine and cinchonine tosylates $\mathbf{4 a}$ and $\mathbf{4 b}$ has been employed for the explanation of this phenomenon. We have found that the vinyl group can take part in the tethering effect inside molecule $\mathbf{4} \mathbf{b}^{+}-\mathrm{H}$ and it can prevent rotation that leads to conformation necessary for hydrolysis in the aqueous acid medium. Therefore, this molecule is less prone to $\mathrm{S}_{\mathrm{N}} 2$ hydrolysis and it reacts in the Pasteur-type quinuclidine ring cleavage process leading to the new derivative, cinchonicine enol tosylate 5. (Z)-Alkene geometry is determined on the basis of the X-ray structure of the sulfonamide $\mathbf{6}$ as derivative of $\mathbf{5}$. Therefore the stereoselective syn-E2 
of quinuclidine ring-opening process, competing to the $S_{N} 2$ hydrolysis is postulated for the formation of the product 5. This product is almost selectively formed from cinchonidine or cinchonine tosylates $(\mathbf{4 a}$ or $\mathbf{4 b})$ with salicylic acid solution under controlled microwave irradiation and can be synthesized by this route in the preparative scale. The new compound is the chiral alkene and can be used as building block ${ }^{23}$ for asymmetric synthesis, including chiral self-organized nanopolymers, similar to those we have just started to obtain. ${ }^{24}$

\section{Experimental Section}

General. Commercial Cinchona alkaloids from Fluka were used. Other reagents and solvents were purchased from commercial suppliers (Sigma-Aldrich) and used without further purification. The course of reactions was monitored by thin-layer chromatography (aliquots were taken and extracted by ethyl ether in the presence of ammonia), which was carried out on 0.25 mm Merck silica gel (60 F254) plates on aluminium. Pure products were isolated by CC over Merck silica gel 60 (230-400 mesh). The column output was monitored with TLC (on aluminium sheets precoated with silica gel $60_{254}$, Merck). Melting points (uncorrected) were determined on the Bëthius apparatus. The optical rotations were measured on a Perkin Elmer 241 polarimeter. High resolution mass spectra were measured on AMD 604 (Inectra $\mathrm{GmbH}$ ) spectrometer. The ${ }^{1} \mathrm{H}$ and ${ }^{13} \mathrm{C}$ NMR spectra were recorded with MERCURY $400 \mathrm{BB}$ or VARIAN 400MR spectrometer $\left({ }^{1} \mathrm{H} ; 400 \mathrm{MHz},{ }^{13} \mathrm{C}: 100 \mathrm{MHz}\right)$. Chemical shifts are given relative to TMS $(\delta=0)$ in ppm and refer to residual solvent as internal standard. All compounds were determined to be > $96 \%$ pure by ${ }^{1} \mathrm{H}$ NMR analysis. IR spectra (KBr pellets) were recorded on FT-IR MAGNA 769 (Nicolet).

\section{General procedure for the Method A tosylation exemplified by the synthesis of $\mathbf{4 b}$}

Tosyl chloride $(3.81 \mathrm{~g}, 20 \mathrm{mmol})$, tributylamine $(0.25 \mathrm{~mL}, 1 \mathrm{mmol})$ and $35 \%$ potassium hydroxide aqueous solution $(50 \mathrm{~mL})$ were added to a stirred solution of cinchonine $\mathbf{2 b}(2.94 \mathrm{~g}$, $10 \mathrm{mmol}$ ) in dichloromethane $(150 \mathrm{~mL})$. The resulting mixture was stirred at $20^{\circ} \mathrm{C}$ for $24 \mathrm{~h}$ (the monitoring of cinchonine conversion on silica gel TLC plates with a mixture of ethyl acetate and methanol 10:1). Then water $(100 \mathrm{~mL})$ was added and stirred for $10 \mathrm{~min}$. The organic phase was separated and washed by water ( 3 x $50 \mathrm{~mL}$ ) and extracted with cold $1 \mathrm{M}$ hydrochloric acid $(5 \mathrm{x}$ $25 \mathrm{~mL})$. The aqueous phase was washed with diethyl ether $(3 \times 25 \mathrm{~mL})$ and then $2 \mathrm{~N} \mathrm{NaOH}$ was added until $\mathrm{pH}>10$. The mixture was extracted with dichloromethane $(4 \mathrm{x} 50 \mathrm{~mL})$ and the combined organic extracts were washed with water $(2 \times 30 \mathrm{~mL})$ and dried with $\mathrm{Na}_{2} \mathrm{SO}_{4}$. The solvent was evaporated under reduced pressure and crude product $\mathbf{4 b} ; 4.25 \mathrm{~g}, 95.0 \%$ (containing a trace amount of starting alkaloid $\mathbf{2 b}$, TLC indicated), as white precipitate was obtained. After column chromatography with ethyl acetate-methanol 20:1, pure 4b 4.03g, $90 \%$ was obtained. 
$\boldsymbol{O}$-tosylcinchonine (4b) M.p. $174-175^{\circ} \mathrm{C},[\alpha]_{\mathrm{D}}{ }^{27}+35.9^{\circ}$ (c 1.00, in EtOH anhyd,); (lit. ${ }^{11 \mathrm{a}}$ m.p. $173{ }^{\circ} \mathrm{C},[\alpha]_{\mathrm{D}}{ }^{20}+51^{\circ}(c 1$ in $96 \% \mathrm{EtOH})$; IR $(\mathrm{KBr}) \mathrm{cm}^{-1}: 3069,29392867,1635,1592,1511$, 1454, $1363\left(\mathrm{SO}_{2}\right), 1242,1189,1174\left(\mathrm{SO}_{2}\right), 1095,1058,1021,987,935,870,811,760,667$, 555; ${ }^{1} \mathrm{H}$ NMR $\left(400 \mathrm{MHz}, \mathrm{CDCl}_{3}\right) \delta(\mathrm{ppm}): 8.68\left(\mathrm{~d},{ }^{3} J=4.4 \mathrm{~Hz}, 1 \mathrm{H}, \mathrm{H}-2{ }^{\prime}\right), 7.98\left(\mathrm{~d},{ }^{3} J=7.6 \mathrm{~Hz}\right.$, 1H, H-8'), 7.97 (bs, 1H, H-5'), 7.67 (t, ${ }^{3} J=7.6$ Hz., 1H, H-7'), 7,51 (t, ${ }^{3} J=7.6$ Hz, 1H,.H-6'), 7.33 (d, ${ }^{3} J=7.2 \mathrm{~Hz}, 2 \mathrm{H}, \mathrm{H}-2$ ', H-6”), 7.21 (bs, 1H, H-3'), 6.78 (d, 2H, ${ }^{3} J=7.2 \mathrm{~Hz}, \mathrm{H}-3$ ", H-5”), 6.10 (bs, 1H, H-9), 5.98 (ddd, $\left.{ }^{3} J=17.6,10.6,7.7 \mathrm{~Hz}, 1 \mathrm{H}, \mathrm{H}-10\right), 5.12-5.05$ (m, 2H. H2-11), 3,30 (s-br, 1H, H-8), 2.82-2.76 (m, 2H, H-2, H-6), 2.64-2.56 (m, 2H, H-2, H-6), 2.28-218 (m, 1H, H3), 2.16 (s, 3H, H ${ }_{3} \mathrm{CAr}$ ), 1-92-1.84 (m, 1H H-5), 1.84-1.78 (m, 1H, H-7), 1.76-1.65,m, 1H, H-4), 1.54-1.48 (m, 2H, H-5. H-7); ${ }^{13} \mathrm{C}$ NMR (100 MHz, $\mathrm{CDCl}_{3}$ ) $\delta: 149.4$ (C-2'), 148.1, (C-4'), 144.5 (C-9'), 143.9 (C-4”), 139.9 (C-10), 132,9 (C-1”), 130,2 (C-3”, C-5”), 129.0 (C-8'), 128.8 (C7'), 127,5 (C-2"' and C-6”), 126.7, (C-6’) 125.5 (C-10'), 122.9 (C-5'), 119.5 (C-3'), 114.9 (C11), 76.2 (C-9), 60.3 (C-8), 49.6 (C-2), 48.7 (C-6), 39.7 (C-3), 27.6 (C-7), 26.2 (C-5), 24.5 (C-4), $21.3\left(\mathrm{H}_{3} \underline{\mathrm{CAr}}\right)$.

The products 3a, 3b and $\mathbf{4 a}$ are obtained from 1a, $\mathbf{1 b}$ and $\mathbf{2 a}$ with tosyl chloride in the excess given in Table 1 (together with $R_{f}$ values of products). Their physicochemical and spectral data are reported below.

$\boldsymbol{O}$-tosylquinine (3a). Crude (92\%), an oily form; pure $(80 \%)$, m.p. $58-60^{\circ} \mathrm{C},[\alpha]_{\mathrm{D}}^{27}+11.7^{\circ}(c$ 1.00 in $99.8 \% \mathrm{EtOH})$; $\left(\mathrm{lit}^{12}\right.$ oil, $[\alpha]_{\mathrm{D}}{ }^{21}+9.8^{\circ}$ (c 1.02 in $\left.96.0 \% \mathrm{EtOH}\right) ;$ IR $(\mathrm{KBr}), \mathrm{cm}^{-1}: 3071$, 2938, 2867, 1621, 1596, 1508, 1475, 1453, $1362\left(\mathrm{SO}_{2}\right), 1304,1263,1226,1186,1175\left(\mathrm{SO}_{2}\right)$, 1091, 1029, 989, 930, 919, 862, 811, 766, 668, 569, 550; ${ }^{1} \mathrm{H}$ NMR (400 MHz, $\left.\mathrm{CDCl}_{3}\right) \delta(\mathrm{ppm})$ : $8.51\left(\mathrm{~d},{ }^{3} J=4.4 \mathrm{~Hz}, 1 \mathrm{H}, \mathrm{H}-2\right.$ ') 7.86 (d, ${ }^{3} J=9.2 \mathrm{~Hz}, 1 \mathrm{H}, \mathrm{H}-8^{\prime}$ ), $7.31-7.25$ (m, 3H, H-7', H-2”, H6”), 7.15 (bs, 2H, H-3', H-5'), 6.76 (d, ${ }^{3} J=7.2$ Hz, 2H, H-3”, H-5”), 6.10 (bs, 1H, H-9) 5.81 (ddd, $\left.{ }^{3} J=17.2,9.87 .4 \mathrm{~Hz}, 1 \mathrm{H}, \mathrm{H}-10\right), 5.02-4.95$ (m, 2H, H2-11), 3.93 (s, 3H, MeO), 3.30 (bs, 1H, H-8), 3.14-3.05 (m, 1H, H-6), 2.98-2.90 (m, 1H, H-2), 2.64-2.56 (m, 1H, H-2), 2.54-2.46 (m, 1H, H-6), 2.28-2.20 (m, 1H, H-3), 2.15 (s, 3H, Me-Ar), 1.92-1.86 (m, 1H, H-4), 1.79-1.60 (m, $2 \mathrm{H}, \mathrm{H}-5, \mathrm{H}-7), 1.58-1.42$ (m, 2H, H-5, H-7). ${ }^{13} \mathrm{C} \mathrm{NMR}\left(100 \mathrm{MHz}, \mathrm{CDCl}_{3}\right) \delta$ (ppm): $157.8(\mathrm{C}-6$ '), 146.9 (C-2'), 144.5 (C-4'), 1.44 .3 (C-4”), 141,9 (C-9'), 141.6 (C-10), 133.7 (C-1”), 133.0 (H-8'). 131.6 (H-3”, H-5”), 128,8 (H-8'), 127.4 (C-2”, C-6”), 126.5 (C-10'), 121.6 (H-3'), 118.8 (H-7'), 114.4 (C-12), 100.4 (C-5'), 79.7 (C-9), 60.3 (C-8), 56.3 (C-6), 55.9 (H H $\left._{3}-\mathrm{O}\right), 42.3$ (C-2), 39.5 (C-3), 27.4 (C-5), 27.2 (C-7), 25.0 (C-4), 21.3 (H ${ }_{3}$ CAr.).

$\boldsymbol{O}$-tosylquinidine (3b). Crude; $(85 \%)$, oily; pure $(76 \%)$, m.p. $119-120^{\circ} \mathrm{C}$; $[\alpha]_{\mathrm{D}}{ }^{27}+23.5^{\circ}(c 1.00$ in $99.8 \%$ EtOH); (lit. ${ }^{12}$ m.p. $116-118^{\circ} \mathrm{C}[\alpha]_{\mathrm{D}}{ }^{21}+28.3^{\circ}(c 1.02$ in $96.0 \% \mathrm{EtOH})$; IR $(\mathrm{KBr}), \mathrm{cm}^{-1}$, 3072, 3011, 2935, 2869, 1621, 1596, 1509, 1475, 1454, $1364\left(\mathrm{SO}_{2}\right), 1302,1225,1189,1176$ $\left(\mathrm{SO}_{2}\right), 1090,1027,989,918,856,818,764,666,570,550 ;{ }^{1} \mathrm{H} \mathrm{NMR}\left(400 \mathrm{MHz}, \mathrm{CDCl}_{3}\right) \delta: 8.53$ $\left(\mathrm{d},{ }^{3} J=4.4 \mathrm{~Hz}, 1 \mathrm{H}, \mathrm{H}-2^{\prime}\right), 7.88$ (d, $\left.{ }^{3} J=9.2 \mathrm{~Hz}, 1 \mathrm{H}, \mathrm{H}-8^{\prime}\right), 7.40-7.32$ (m, 2H, H-3', H-5'), 7.30 (dd, ${ }^{3} J=9.2 \mathrm{~Hz},{ }^{4} J=2.0 \mathrm{~Hz}, 1 \mathrm{H}, \mathrm{H}-7$ ') 7.15 (d, ${ }^{3} J=7.6 \mathrm{~Hz}, 2 \mathrm{H}, \mathrm{H}-2$ ', H-6”), 6.82 (d, ${ }^{3} J=7.6$ Hz, 2H, H-3", H-5”), 6.13 (bs, 1H, H-9), 5.97 (ddd, ${ }^{3} J=17.2,10.8,7.2$ Hz, 1H, H-10), 5.12-505 (m, 2H, $\mathrm{H}_{2}-11$ ), 3,93 (s, 3H, $\mathrm{H}_{3} \mathrm{C}-\mathrm{O}$ ), 3.20 (bs, 1H, H-8), 2.87-2.77 (m, 2H, H-2, H-6), 2.68-2.57 
(m, 2H, H-2, H-6), 2.29-219 (m, 1H, H-3), 2.17 (s, 3H,. H$\left._{3} \mathrm{CAr}\right), 1.96-1.85$ (m, 1H, H-4), $1.83-$ 1.78 (m, 1H, H-5), 1.72-158 (m, 1H, H-7), 1.54-1.47 (m, 2H, H-5. H-7); ${ }^{13} \mathrm{C}$ NMR (100 MHz,

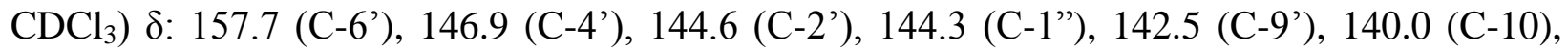
133.0 (C4”), 131.6 (C3”, C5”), 128.9 (C8'), 127.5 (C2”, C6”), 126.6 (C10’), 121.6 (C3') 118.7 (C-7’) 115.0 (C-11), 100.4 (C-5’), 79.4 (C-9), 60.5 (C-8), 55.4 (H3ㅡㄹ), 49.7 (C-2), 49.0 (C-6), 39.7 (C-3), 27.6 (C-5), 26.22 (C-7), 23.9 (C-4), 21.3 (H H $_{3}$ Ar).

O-tosylcinchonidine (4a). Crude (91 \%) m.p. $125-127{ }^{\circ} \mathrm{C}$, pure $(82.0 \%)$, m.p. $134-135{ }^{\circ} \mathrm{C}$, $[\alpha]_{\mathrm{D}}{ }^{27}+3.8 .^{\circ}(c 1.00$ in $99.8 \% \mathrm{EtOH}) ;\left(\right.$ lit. $^{12}[\alpha]_{\mathrm{D}}{ }^{20}+3.1^{\circ}(c 0.03,96.0 \% \mathrm{EtOH}) ; \quad$ IR $(\mathrm{KBr}) \mathrm{cm}^{-}$ 1: 3071, 2968, 2941, 2870. 1621, 1596, 1511, 1455, 1433, $1361\left(\mathrm{SO}_{2}\right), 1263,1190,1173\left(\mathrm{SO}_{2}\right)$, 1096, 1030, 1018, 989, 930, 868, 804, 759, 672, 572; ${ }^{1} \mathrm{H}$ NMR (400 MHz, $\left.\mathrm{CDCl}_{3}\right), \delta: 8.66\left(\mathrm{~d},{ }^{3} J\right.$ $\left.=4.0 \mathrm{~Hz}, 1 \mathrm{H}, \mathrm{H}-2^{\prime}\right), 7.98$ (d, $\left.{ }^{3} J=8.0 \mathrm{~Hz}, 2 \mathrm{H}, \mathrm{H}-5^{\prime}, \mathrm{H}-8^{\prime}\right), 7.67$ (t, ${ }^{3} J=8.3 \mathrm{~Hz}, 1 \mathrm{H} . \mathrm{H}-7$ ') $, 7,56-$ 7.48 (m, 1H, H-6'), 7.29 (d, 2H, ${ }^{3} J=7.7$ Hz, H-2", H-6"), 7.19 (bs, 1H, H-3'), 6.73 (d, ${ }^{3} J=7.7$ Hz, 2H, H-3", H-5”), 6.08 (bs, H-9), 5.83 (ddd, ${ }^{3} J=17.6 ., 10.4,7.4$ Hz, 1H, HC10), 5.02-4.96 (m, 2H, H $\mathrm{H}_{2}-11$ ), 3,35 (bs, 1H, H-8), 3.12-3.00 (m, 1H, H-6), 2.92 (dd, $1 \mathrm{H},{ }^{2} \mathrm{~J}=13.6,{ }^{3} \mathrm{~J}=9.4 \mathrm{~Hz}$, H-2), 2.56 (ddd, $\left.{ }^{2} J=12.6,{ }^{3} J=10.8,4.4 \mathrm{~Hz}, 1 \mathrm{H}, \mathrm{H}-6\right), 2.51-2.42$ (m, 1H, H-2), 2.28-2.20 (m, $1 \mathrm{H}, \mathrm{H}-3), 2.14$ (s, 3H, $\underline{\mathrm{H}}_{3} \mathrm{CAr}$ ), 2.14-2.0 (m, 1H, H-4), 1.91-187 (m, 1H, H-7), 1.78-1.62 (m, 1H, $\mathrm{H}-5), 1.56-1.48$ (m, 2H, H-5, H-7); ${ }^{13} \mathrm{C} \mathrm{NMR} \mathrm{(100} \mathrm{MHz,} \mathrm{CDCl}_{3}$ ) $\delta: 150.3$ (C-4'), 149.5 (C-2'), 148.1 (C-9'), 144.5 (C-4”), 141.6 (C-10), 133.0 (C-1”), 130,3 (C-3”, C-5”), 129.1 (C-8'), 128.8 (C-7'), 127,5 (C-2”, C-6”), 126.7 (C-6'), 125.8 (C-10'), 123.1 (C-5'), 117.5 (C-3'), 114.5 (C-11), 76.2 (C-9), 60.3 (C-8), 49.6 (C-2), 48.7 (C-6), 39.7 (C-3), 27.6 (C-7), 26.2 (C-5), 24.5 (C-4), $21.3 \mathrm{H}_{3} \underline{\mathrm{CAr}}$.

Method B: Solid-liquid phase $O$-tosylation: is given in the Supplementary Material. Hydrolysis of $\boldsymbol{O}$-tosyl derivatives by conventional Procedure 1 to 9-eipibases 1c, 1d, 2c, 2d and their ${ }^{1} \mathrm{H}$ NMR and ${ }^{13} \mathrm{C}$ NMR spectra are given in the Supplementary Material.

General characterization data: for obtained 9-epibases 1c,d, $\mathbf{2 c , d}$ are given below.

9-Epiquinine (1c). Oil, $[\alpha]_{\mathrm{D}}{ }^{27}+42.5^{\circ}(\mathrm{c} 1.24,99.8 \%$ EtOH $) ;\left\{\right.$ lit. $^{12}$ oil, $[\alpha]_{\mathrm{D}}{ }^{20}+50.4^{\mathrm{o}}(\mathrm{c} 0.442$, $99.0 \% \mathrm{EtOH})$, lit ${ }^{17 \mathrm{~b}}[\alpha]_{\mathrm{D}}{ }^{28}+39.9^{\circ}(\mathrm{c} 1.13$ in $\left.\mathrm{EtOH})\right\}$.

9-Epiquinidine (1d). M.p. $114-115^{\circ} \mathrm{C},[\alpha]_{\mathrm{D}}{ }^{27}+105.5^{\circ}$ (c 1.00, 99.8\% EtOH); $\left\{\right.$ lit. ${ }^{12}$ m.p. $112-$ $113^{\circ} \mathrm{C},[\alpha]_{\mathrm{D}}{ }^{2}+103.7^{\circ}$ (c 1.05 in EtOH anhydrous), lit ${ }^{17 \mathrm{~b}}[\alpha]_{\mathrm{D}}{ }^{26}+96.3^{\circ}$ (c 1.15 in EtOH) $\}$.

9-Epicinchonidine (2c). M.p. $109-110^{\circ} \mathrm{C},[\alpha]_{\mathrm{D}}{ }^{27}+60.8^{\circ}$ (c 1.00, $99.8 \%$ EtOH), $\left\{\right.$ lit. $^{12}$ m.p. $101-104^{\circ} \mathrm{C},[\alpha]_{\mathrm{D}}{ }^{19}+69.7^{\circ}(\mathrm{c} 0.80$, EtOH $99.5 \%)$ lit. $^{17 \mathrm{~b}}[\alpha]_{\mathrm{D}}{ }^{28}+56.9^{\circ}$ (c 1.15 in EtOH $\left.)\right\}$.

9-Epicinchonine (2d). M.p. $89-90{ }^{\circ} \mathrm{C},[\alpha]_{\mathrm{D}}{ }^{27}+116.4^{\circ}$ (c 1.00, $99.8 \%$ EtOH); $\left\{\right.$ lit. $^{12}$ m.p.85-87 ${ }^{\circ} \mathrm{C},[\alpha]_{\mathrm{D}}^{27}+122.0^{\circ}(c 1.00,99.5 \%$ EtOH $)$ lit. $^{17 \mathrm{~b}}[\alpha]_{\mathrm{D}}{ }^{26}+114.5^{\circ}(\mathrm{c} 1.07$ in EtOH$\left.)\right\}$.

Procedure 2. Hydrolysis of tosylate $4 \mathrm{~b}$ under microwave irradiation in the medium of tartaric acid is given in the Supplementary Material.

Procedure 3. Hydrolysis of tosylates $4 \mathrm{a}$ and $4 \mathrm{~b}$ under controlled microwave irradiation in the medium of salicylic acid toward cinchonicine enol tosylate 5 formation: Tosylate $\mathbf{4 b}$ (or 
4a) $(0.90 \mathrm{~g}, 2 \mathrm{mmol})$ and salicylic acid $(20 \mathrm{mmol})$ were placed in a Pyrex cylindrical vessel and $20 \mathrm{~mL}$ of $50 \%$ ethylene glycol was added. The reaction mixture was subjected to microwave irradiation at $95^{\circ} \mathrm{C}$. The full conversion of substrate $\mathbf{4 b}$ was observed (TLC, EtOAc-EtOH=10:1) after 30 minutes (4a after $15 \mathrm{~min}$ ). The reaction mixture was extracted with dichloromethane in the presence of an excess of cold sodium hydroxide $20 \%$ solution. The organic phase was dried with anhydrous sodium sulfate and the organic solvent was removed under reduced pressure. The yields and $R_{f}$ values of products obtained from $\mathbf{4 b}$ after CC separation are given in Table 2, entry 6. Product $5(0.54 \mathrm{~g}, 60 \%)$ was isolated using the mixture methoxyethanol/methanol 5:1) as a colorless oil substance: $[\alpha]_{\mathrm{D}}{ }^{20}+33.2^{\circ}(c 1.08$ in $99.8 \% \mathrm{EtOH})$.

\section{(Z)-1-(Quinolin-4-yl)-3-((3R,4R)-3-vinylpiperidin-4-yl)prop-1-enyl}

\section{4-methylbenzene}

sulfonate (5). IR (KBr) cm c $^{-1}$ (m-middle, s-strong): 3066 (m), 3030 (m), 2922 (s), 2854 (m) 2802 (m), 2733 (m), 1693 (m), 1637 (m), 1586 (m), 1506 (s), 1444 (m), 1373 (s, SO $), 1268$ (m), 1188 (s, $\mathrm{SO}_{2}$ ), 1177 (s), $1092(\mathrm{~m}) ;{ }^{1} \mathrm{H} \mathrm{NMR}\left(400 \mathrm{MHz}, \mathrm{CDCl}_{3}\right) \delta: 8.51$ (d, ${ }^{3} J=4.5 \mathrm{~Hz}, 1 \mathrm{H}, \mathrm{H}-2^{\prime}$ ), $7.95\left(\mathrm{dd},{ }^{3} J=7.8,{ }^{4} J=1.6 \mathrm{~Hz}, 1 \mathrm{H}, \mathrm{H}-8^{\prime}\right), 7.93$ (dd, ${ }^{3} J=7.8,{ }^{4} \mathrm{~J}=1.2 \mathrm{~Hz}, 1 \mathrm{H}, \mathrm{H}-5$ '), 7.62 (ddd, $\left.1 \mathrm{H},{ }^{3} J=8.2,7.8,{ }^{4} J=1.2,1 \mathrm{H}, \mathrm{H}-7^{\prime}\right), 7.45\left(\mathrm{ddd},{ }^{3} J=8.2,7.8,{ }^{4} J=1.6 \mathrm{~Hz}, 1 \mathrm{H}, \mathrm{H}-6\right.$ '), 7.27 (d, $\left.\left.{ }^{3} J=8.2 \mathrm{~Hz}, 2 \mathrm{H}-o-\mathrm{SO}_{2} \mathrm{Ar}\right)\right), 7.21\left(\mathrm{~d},{ }^{3} J=4.5 \mathrm{~Hz}, 1 \mathrm{H} . \mathrm{H}-3\right.$ '), $6.78\left(\mathrm{~d},{ }^{3} J=8.2 \mathrm{~Hz}, 2 \mathrm{H}-m-\mathrm{SO}_{2} \mathrm{Ar}\right)$, $6.10\left(\mathrm{ddd},{ }^{3} J=17.0,10.3,7.6 \mathrm{~Hz}, 1 \mathrm{H}, \mathrm{HC} 10\right), 5.75\left(\mathrm{t},{ }^{3} J=7.6 \mathrm{~Hz}, 1 \mathrm{H}, \mathrm{H}-8\right), 5.17\left(\mathrm{dd},{ }^{3} J=\right.$ $\left.10.3,{ }^{2} J=2.0 \mathrm{~Hz}, 1 \mathrm{H}, \mathrm{H}-11\right), 5.09\left(\mathrm{dd},{ }^{3} \mathrm{~J}=17.0,{ }^{3} \mathrm{~J}=2.0 \mathrm{~Hz}, 1 \mathrm{H}, \mathrm{H}-11\right), 3.09$ (ddd, ${ }^{2} J=12.4$ $\left.\mathrm{Hz},{ }^{3} J=3.6 \mathrm{~Hz}^{3} J=3.4 \mathrm{~Hz}, 1 \mathrm{H}, \mathrm{H}_{\text {eqat }}-6\right), 2.97\left(\mathrm{dd},{ }^{2} J=14.8 \mathrm{~Hz},{ }^{3} J=3,4 \mathrm{~Hz}, 1 \mathrm{H}, \mathrm{H}_{\text {eqat }}-2\right), 2.83$ $\left(\mathrm{dd},{ }^{2} J=14.8 \mathrm{~Hz}, 3.6 \mathrm{~Hz}, 1 \mathrm{H}, \mathrm{H}_{\text {axial }}-2\right), 2.65\left(\mathrm{ddd},{ }^{2} J=12.4 \mathrm{~Hz},{ }^{3} J=10.8 \mathrm{~Hz},{ }^{3} J=3.6 \mathrm{~Hz}, 1 \mathrm{H}\right.$, $\mathrm{H}_{\text {axial }}-6$ ), 2.36-2.20 (m, 3H, H-3, $\mathrm{H}_{2}-7$ ), 2.17, s, $\left.\underline{\mathrm{H}}_{3} \mathrm{CAr} 3 \mathrm{H}\right), 1.82-1.73$ (m, 1H, H-4) 1.68-1.44 $\left(\mathrm{m}, 2 \mathrm{H}, \mathrm{H}_{2}-5\right),{ }^{13} \mathrm{C}$ NMR (100 MHz, $\mathrm{CDCl}_{3}$ ) $\delta: 162.3$ (C-9), 150.2 (C-2'), 148.2 (C-9'), 145.6 (C-1”), 144.8 (C-4'), 141.0 (C-4”), 137.3 (C-11), 130.2 (C-3”, C-5”), 129.9 (C-8'), 129.6 (C-7'), 127.9 (C-6’), 127.5 (C-2”, C-6”), 126.0 (C-10’), 125.7 (C-5’), 121.8 (C-11), 117.7 (C-2'), 116.5 (C-8, 51.0 (C-2), 46.7 (C-6), 43.1 (C-3), 39.6 (C-4), 35.1 (C-5), 28.5 (C-7), $21.4\left(\mathrm{H}_{3} \mathrm{CAr}_{3}\right)$; HRMS (ESI, $[\mathrm{M}+\mathrm{H}]^{+}$) found: 449.1905, calcd for $\mathrm{C}_{26} \mathrm{H}_{29} \mathrm{~N}_{2} \mathrm{O}_{3} \mathrm{~S}: 449.1899$.

Synthesis of sulfonamide (60). To the solution of $5(224 \mathrm{mg}, 0,5 \mathrm{mmol})$ in $\mathrm{CH}_{2} \mathrm{Cl}_{2}(20 \mathrm{~mL})$ tosyl chloride $143.0 \mathrm{mg}, 0.75 \mathrm{mmol})$, tributylamine $(0,012 \mathrm{~mL}, 0,05 \mathrm{mmol})$ and $35 \% \mathrm{KOH}$ solution $(10 \mathrm{~mL})$ were added. Substrate was disappeared in reaction mixture (TLC control) after 15 min stirring at room temperature. The organic phase was separated and washed by water, dried and evaporated. White solid was obtained (283 mg, 94.0\%). After column chromatography with using of the ethyl acetate as eluent, pure 6 was obtained $(260 \mathrm{mg}, 86.4 \%)$, m.p. $154-155^{\circ} \mathrm{C}$. Solid was dissolved in the mixture 1:1 hexane-ethyl ether and was stored to crystallization. White crystals were obtained, m.p. $156.0-156.5^{\circ} \mathrm{C}$ which were used for X-ray measurements.

(Z)-1-(quinolin-4-yl)-3-((3R,4R)-1-tosyl-3-vinylpiperidin-4-yl)prop-1-enyl methylbenzenesulfonate (6). ${ }^{1} \mathrm{H} \mathrm{NMR} \mathrm{NMR}\left(400 \mathrm{MHz}, \mathrm{CDCl}_{3}\right) \delta: 8.70,\left(\mathrm{~d},{ }^{3} \mathrm{~J}=4.1 \mathrm{~Hz}, 1 \mathrm{H}, \mathrm{H}-\right.$ 2'), 7.94 (d, ${ }^{3} J=8.6 \mathrm{~Hz}, 1 \mathrm{H}, \mathrm{H}-8^{\prime}$ ), 7.86 (d, ${ }^{3} J=8.6 \mathrm{~Hz}, 1 \mathrm{H}, \mathrm{H}-5$ '), 7.63-7.59 (m, 3H, H-7' $+2 \mathrm{x}$ $\left.\mathrm{H}-o-\mathrm{OSO}_{2} \mathrm{Ar}\right), 7.43\left(\mathrm{dd},{ }^{3} J=8.6,8.2 \mathrm{~Hz}, 1 \mathrm{H}, \mathrm{H}-6\right.$ ') $7.30\left(\mathrm{~d}^{3} J=8.1 \mathrm{~Hz}, 2 \mathrm{H}, 2 \mathrm{H}-o-\mathrm{NHSO}_{2} \mathrm{Ar}\right)$, 
$7.21\left(\mathrm{~d},{ }^{3} J=8.1 \mathrm{~Hz}, 2 \mathrm{H}, 2 \mathrm{H}-m-\mathrm{NHSO}_{2} \mathrm{Ar}\right), 7.17\left(\mathrm{~d},{ }^{3} J=4.1 \mathrm{~Hz}, 1 \mathrm{H}, \mathrm{H}-3{ }^{\prime}\right), 6.74\left(\mathrm{~d},{ }^{3} J=8.1 \mathrm{~Hz}\right.$, $2 \mathrm{H}, 2 \mathrm{H}-m-\mathrm{SO}_{2} \mathrm{Ar}$ ), 6.17 (ddd, $\left.{ }^{3} J=17.2,10.2,8.8 \mathrm{~Hz}, 1 \mathrm{H}, \mathrm{H}-10\right), 5.65\left(\mathrm{t},{ }^{3} J=7.7 \mathrm{~Hz}, 1 \mathrm{H}, \mathrm{H}-8\right)$, $5.22\left(\mathrm{~d},{ }^{3} \mathrm{~J}=10,2 \mathrm{~Hz}, 1 \mathrm{H}, \mathrm{H}-11\right), 5.18\left(\mathrm{~d},{ }^{3} \mathrm{~J}=17.2 \mathrm{~Hz}, 1 \mathrm{H}, \mathrm{H}-11\right), 3.69$ (dd, ${ }^{2} J=11.2,{ }^{3} \mathrm{~J}=2.1 \mathrm{~Hz}$, $\left.1 \mathrm{H}, \mathrm{H}_{\text {eqat }}-2\right), 3.58-3.55\left(\mathrm{~m}, 1 \mathrm{H}, \mathrm{H}_{\text {equat }}-6\right), 2.53\left(\mathrm{dd},{ }^{2} J=11.2,{ }^{3} J=3.0 \mathrm{~Hz}, 1 \mathrm{H}, \mathrm{H}_{\text {axial }}-2\right), 3.44-$ 3.38 (m, 2H, H-3, $\mathrm{H}_{\text {axial }}-6$ ), 3.40 (s, 3H, $\underline{\mathrm{C}}_{3} \mathrm{Ar}$ ), 2,26 (dd, ${ }^{3} \mathrm{~J}=17.4,7.7 \mathrm{~Hz}, 2 \mathrm{H}, \mathrm{H}_{2}-7$ ), 2.15 (s, $\left.3 \mathrm{H}, \underline{\mathrm{H}}_{3} \mathrm{CAr}\right), 1.68-1.56$ (m, 3H, H-4, $\left.\mathrm{H}_{2}-5\right) .{ }^{13} \mathrm{C}$ NMR (100 MHz, $\mathrm{CDCl}_{3}$ ) $\delta: 163.2$ (C-9), 149.2 (C-2'), 147.9 (C-9'), 144.9 (C-1”), 144.3 (HC-4'), 143.4 (C-1"'), 140.2 (C-10), 138.2 (C-4”), 137.5 (C-4"”), 134.9 (2xC-m-Ar"), 132.9 (2xC-m-Ar"”), 129.5 (2xC-o-Ar"), 129.3 (C-8'), 128.7 (C7'), 127.5 (2xC-o-Ar'”), 126.9 (C-6'), 126.1 (C-10') 125.4 (C-5'), 125.2 (C-8), 121.2 (C-3'), 118.0 (C-11), 50.7 (C-2), 46.0 (C-6), 42.0 (C-4), 38.4 (C-3), 29.3 (C-5), 27.1 (C-7), 21.5 (Ar"'$\left.\mathrm{CH}_{3}\right), 21.2\left(\mathrm{Ar}-{ }^{\prime \prime} \mathrm{CH}_{3}\right)$.

Supplementary Materials: Additional experimental procedures, X-ray data, ${ }^{1} \mathrm{H}$ NMR and ${ }^{13} \mathrm{C}$ NMR spectra.

\section{Acknowledgements}

The authors thank Professor Barbara Oleksyn from the Jagiellonian University in Krakow for fruitful discussions.

\section{References}

1. Antimalarial activity: (a) Thompson, A. J.; Lochner, M. and Lumins, S. C. R. Br. J. Pharm. 2007, 151, 666. (b) Pukrittayakamee, S.; Chantra, A.; Vanijanonta, S.; Clemens, R.; Looareesuwan, S.; White, N. J. Antimicrob. Agents Chemother. 2000, 44, 2395. (c) Demar, M.; Crame, B. Am. J. Trop. Med. Hyg. 2004, 70, 125.

2. Antiarrythmic activity: (a) Grace, A. A. and Camm, A. J. N. Engl. J. Med. 1998, 338, 35. (b) RuDusky, B. M. Chest, 2001, 119, 1617.

3. Asymmetric catalysts: (a) Kacprzak, K.; Gawroński, J. Synthesis 2001, 961. (b) France, S.; Guerin, D. J.; Miller, S. J.; Lectka, T. Chem. Rev. 2003, 103, 2985. (c) Ooi, T.; Maruoka, K. Angew. Chem. Int. Ed. 2007, 46, 4222. (d) Marceli, T.; Hiemstra H. Synthesis 2010, 1229.

4. Song, E. C., Ed. Cinchona Alkaloids in Synthesis and Catalysis Wiley-VCh: Weinheim, 2009.

5. (a) Prelog, V.; Häfliger, O. Helv. Chim. Acta, 1950, 33, 2021. (b) Hoffmann, H. M. R. Frackenpohl, J. Eur. J. Org. Chem. 2004, 4293. (c) Kaufman, T. S.; Rúveda, E.A. Angew. Chem. Int. Ed. 2005, 44, 854.

6. (a) Verpoorte, R.; Schripsema, J.; Der Leer, T. V. In The Alkaloids, Chemistry and Pharmacology Brossi, A., Ed., Academic Press: San Diego, 1988, Vol. 34, pp 331-398. (b) 
Verpoorte, R. In Monoterpenoid indole alkaloids, supplement to Vol 25, Saxton, J. E., Wiley: New York, 1994, Part 4, pp 647-687.

7. (a) Karle, J. M.; Karle, I. L.; Gerena, L.; Milhous, W. K.; Antimicrob. Agents Chemother. 1992, 36, 1538. (b) Karle. J. M.; Bhattacharjee, A. K. Bioorg. Med. Chem. 1999, 7, 1769.

8. (a) Rabe, P. Lieb. Ann. 1932, 492, 242. (b) Rabe, P.; Haeusler, H.; Hochstetätter, W. Lieb. Ann. 1934, 514, 61.

9. (a) Dijkstra, G. D. H.; Kellog, R. M.; Wynberg, H.; Svendsen, J. S.; Marko, I.; Sharpless, K. J. Am. Chem Soc. 1989, 111, 8076. (b) Dijkstra, G. D. H.; Kellog, R. M.; Wynberg, H. J. Org. Chem. 1990, 55, 6121. (c) Silva, T. H. A.; Oliveira, A. B.; Dos Santos, H. F.; De Almeida, W. B. Struct. Chem. 2001, 12, 432. (d) Caner, H.; Biedermann, P. U.; Agranat, I. Chirality 2003, 15, 637.

10. (a) Akasaka, K.; Gyimesi-Forras, K.; Lammerhofer, M.; Fujita, T.; Watanabe, M.; Harada, N.; Lindner, W. Chirality 2005, 17, 544. (b) Busigin, I.; Nieminen, A.; Taskinen, A.; Sinkkonem, J.; Taukoniitty, E.; Silanpaa, D. Y.; Leino, R. J. Org. Chem. 2008, 73, 6559. (c) Ucello-Barretta, G.; Vanni, L.; Balzano. F. Eur. J. Org. Chem. 2009, 860.

11. (a) Suszko, J.; Tomanek, A. .Recl. Chim. Pays Bas, 1933 13, 18. (b) Fiediuszko, J.; Suszko, J. Bull. Int. Acad. Sci. Lett. Cl. Sci Math. Nat. Ser. A, 1934, 413; Chem. Abstr. 1935, 29, 2961. (c) Ludwiczakówna, R.; Suszko, J. Arch. Chem. Farm. (Pol.) 1935, 2, 196; Chem. Abstr. 1936, 30, 1061. (d) Suszko, J.; Szelag, F. Rocz. Chem. 1934, 14, 1202; Chem. Abstr. 1935, 29, 642. (e) Suszko, J.; Szelagg, F. Bull. Int. Acad. Sci. Lett. Cl. Sci Math. Nat. Ser. A, 1936, 30, 403; Chem. Abstr, 1937, 31, 1813.

12. Szelag, F., Ph.D. Thesis, Suszko, J. (Supervisor), University of Poznań, Poland, 1938.

13. (a) Prajer, L.; Suszko, J. Rocz. Chem.1952, 26, 531; Chem. Abstr. 1955, 49, 2448. (b) Suszko, J.; Szelagg, F. Rocz. Chem. 1952, 26, 555. (c) Suszko, J.; Dega-Szafran, Z. Bull. Acad. Polon. Sci. Ser Sci. Chim. 1964, 12, 607; Chem. Abstr. 1965, 62. 7818b.

14. (a) Braje, W.; Holzgrefe, J.; Wartchow, R.; Hoffmann, H. M. R. Angew. Chem. Int. Ed. 2000, 39, 2085. (b) Röper, S.; Franz, H. H.; Wartchow R.; and Hoffmann, M. H. R. J. Org, Chem. 2003, 68, 4944. (c) Franz, H. H.; Röper, S.; Wartchow R. and Hoffmann, M. H. R. J. Org, Chem. 2004, 69, 2983. (d) Zielińska-Błajet, M.; Kucharska, M.; Skarżewski, J. Synthesis 2006, 1176.

15. Sidorowicz, L.; Skarżewski J. Synthesis 2011, 708.

16. (a) Suszko-Purzycka, A.; Lipińska, T.; Karczmarzyk, Z.; Pniewska, B. Acta Cryst. 1990, C46, 2124. (b) Ciechanowicz-Rutkowska, M.; Oleksyn, B. J.; Suszko-Purzycka, A.; Lipińska, T. J. Pharm. Sci. 1992, 81, 559. (c) Lewiński, K.; Nitek, W.; Oleksyn, B. J.; Kostrzewa,A.; Lipińska, T.; Suszko-Purzycka, A. Acta Cryst. 1996, C52, 3121. (d) Kowalik, J.; Lipińska, T.; Oleksyn, B.; Śliwiński, J. Enantiomer 1999, 4, 389.

17. (a) Kagan, H. B.; Peyronel, J. F. J. Chem. Res. Miniprint FR. 1980, 9, 4057. (b) Hiratake, J.; Inagaki, M.; Yamamoto, Y.; Oda, J. J Chem. Soc. Perkin Trans. 1, 1987, 1053. (c) Brunner, H.; Bügler, J. J. Bull. Soc. Chim. Belg. 1997, 106, 77. (d) Debrage, S.; Violeau, B.; Jouannetaud, M.-P.; Jacquesy, J.-C.; Cousson, A. Tetrahedron 2006, 62, 662. 
18. Yanuka, Y.; Geryes, A.; Heller, M. Tetrahedron 1987, 43, 911.

19. X-Ray reflection intensities for the crystals of $\mathbf{6}$ were measured on a Bruker Nonius Kappa CCD diffractometer. Crystal data are given in the Supplementary Material, CCDC deposition no 836794.

20. Karczmarzyk, Z.; Lipińska, T. M.; Wysocki, W.; Denisiuk, M.; Piechocka, K. Acta Cryst. 2011, C67, 346.

21. (a) Perreaux, L.; Loupy, A. Tetrahedron, 2001, 57, 9199. (b) De La Hoz, A.; Diaz-Ortiz, A.; Moreno, A. Chem. Soc. Rev. 2005, 34, 164. (c) Kuznietsow, D. V.; Raev, V. A.; Kuranow, G. L.; Arapov, O. V.; Kostikow, R. R. Russ. J. Org. Chem. 2005, 41, 1719. (d) Lipińska T. M. Tetrahedron 2006, 62, 5736. (e) Kappe, C. O.; Dallinger, D. Mol.. Divers. 2009, 13, 71.

22. Bren, U.; Krżan, A,; Mavri, J. J. Phys. Chem. A 2008, 112, 166.

23. Willis, M. C.; Brace, G. M.; Holmes. I. P. Angew. Chem. Int. Ed. 2005, 44, 403.

24. (a) Kaczorowski, T.; Justyniak, I.; Lipińska, T.; Lipkowski, J.; Lewiński, J. J. Am. Chem. Soc. 2009, 131, 5393. (b) Lewiński, J.; Kaczorowski, T.; Prochowicz, D.; Lipińska, T.; Justyniak, I.; Kaszkur, Z.; Lipkowski, J. Angew. Chem. Int. Ed. 2010, 49, 7035. 